Resumen por el autor, Charles E. Johnson.

Derivados branguiales en las tortugas.

El tema de este trabajo es el desarrollo de los derivados branquiales de las tortugas, representadas por las formas Chelydra serpentina, Chrysemys marginata y. Trionix sp. El timo persistente se origina en la porción dorsal de la tercera bolsa visceral, mientras que un brote transitorio aparece en conexión con la porción dorsal de la segunda bolsa visceral. Una paratiroides se desarrolla en la porción ventral de la tercera bolsa. La cuarta bolsa no produce ningún órgano persistente y las puebas de la existencia de estructuras transitorias son dudosas. La quinta bolsa origina una paratiroides persistente $y$, aunque faltan pruebas directas, es posible que produzca algunas veces un timo rudimentario.

En estados jóvenes halló el autor con gran constancia un divertículo ultimobranquial bien desarrollado, situado a cada lado del cuerpo, pero el del lado derecho está generalmente destinado a formar una estructura sumamente pequeña, cuando se compara con la del lado izquierdo, y en algunos casos dicha estructura parece faltar por completo en estados más avanzados. Las bolsas cuarta y quinta y el divertículo ultimobranquial se diferencian a expensas de lo que al principio es una sola evaginación de la pared faríngea lateral. La quinta bolsa es de naturaleza rudimentaria y durante un periodo considerable mantiene conexiones celulares con la vesícula ultimobranquial. Esta se caracteriza por la forma vesicular voluminosa que a menudo exhibe. Al llegar la época de salir el embrión del heuvo ha adquirido la estructura de un órgano linfoide.

Translation by José F. Nonidez

Cornell Medieal College, New York 
AUTHOR'S ABSTRACT OF THIS PAPER ISSUED

BY THE BIBLIOQRAPHIC BERVICE, DECEMBER 27

\title{
BRANCHIAL DERIVATIVES IN TURTLES
}

\author{
CHARLES EUGENE JOHNSON \\ Department of Zoology, University of Kansas \\ FIVE PLATES (TWENTY-FOUR FIGURES)
}

INTRODUCTION

Studies on the branchial derivatives of reptiles have been confined chiefly to lizards and snakes. The most recent work on these groups is that of St. Remy et Prenant ('03-'04). In the former group, represented by the genera Anguis and Lacerta, these authors found that a thymus body is formed by the second and third gill pouches only. The derivative of the second pouch is of variable size; whether it persists into the adult stage or not they were unable to determine. The third pouch gives rise also to a persisting epithelial body or parathyreoid. The fourth pouch gives origin only to a transitory epithelial body. The fifth pouch is of very rudimentary nature; it attains the form of a small blind pocket which soon disappears without giving rise to derivatives of any kind. A right and a left ultimobranchial evagination is present in the early stages, but the left one alone is destined to develop into a glandular organ; the right, as a rule, very soon disappears entirely, but in one instance a rudimentary ultimobranchial body was found on this side in an embryo Anguis of $6 \mathrm{~cm}$. length.

In snakes, represented by the genera Coluber and Tropidonotus, a somewhat different condition was found. In this group the first and second gill pouches give rise to rudimentary, transitory thymus bodies, that of the second being the larger. The third pouch likewise produces a transitory thymus bud very similar to that of the first or the second pouch, but in addition

1 Technical assistance for a part of the present work was made possible through the research fund of the University of Kansas. 
there is formed a persisting parathyreoid body. The persisting thymus is developed from the fourth and fifth pouches. In Coluber, moreover, the fourth pouch gives origin to a persisting parathyreoid, while a very rudimentary transitory body of this kind, as a rule, is formed by the fifth pouch. In Tropidonotus, on the other hand, the fifth pouch only exceptionally gives rise to a parathyreoid, which likewise is of transitory nature. The right ultimobranchial evagination does not disappear, as in the lizards, but, like the left, undergoes progressive development into a glandular organ. The two are symmetrically situated in Coluber, but in Tropidonotus the position of the right one is somewhat variable.

For the turtle group very little work appears to have been done in connection with the branchial derivatives. A brief account by van Bemmelen ('93) has reference to Chelonia viridis. According to this account, the earlier phases of the development of the gill pouches correspond with the conditions in lizards and in snakes, but in later stages there is greater similarity with the processes in birds than with those of reptiles. Five pairs of visceral pouches are recognized, of which the first three become perforate, as does probably the fourth pair also. From the second pouch arises an epithelial bud which develops into the anterior lobe of the thymus; but the pouch itself becomes, as in snakes, an isolated vesicle which is destined to disappear, as in the case of the corresponding pouch in birds. The third pouch becomes an expanded epithelial vesicle provided with numerous secondary evaginations. It separates from the epidermal and the pharyngeal epithelium, and the secondary evaginations give rise to the thymous tissue, in the midst of which the central epithelial cyst persists as a homologue of the 'carotid body' of lizards. The fourth and fifth visceral pouches arise simultaneously with the 'suprapericardial' (ultimobranchial) evagination, from a lateral 'blinddarmförmigen Falte' at the caudal end of the pharynx (recessus praecervicalis), in the same way as in snakes. These outpouchings soon become separated from the pharynx and form a complex of three connected vesicles. If these vesicles, says van Bemmelen, in their further development 
were to proceed in the same manner as in the case of the serpents, then the first two, which represent the fourth and fifth pouches, must develop into thymous tissue, while the third and hindmost remains epithelial. But this does not occur; all three maintain an epithelial character, and even in much later stages are found in this condition, situated between the aorta and the pulmonary arch.

\section{MATERIAL AND METHODS}

The present study is based upon a series of sectioned embryos varying in size from $4 \mathrm{~mm}$., greatest length, to newly hatched specimens. The stains employed were borax carmine and Lyon's blue. Wax-plate reconstructions of the structures involved were made from specimens of Chrysemys of $10 \mathrm{~mm}$., greatest length, and of $8 \mathrm{~mm}$. carapace length (c. 1.); and from embryos of Chelydra of lengths of $5 \mathrm{~mm} ., 9 \mathrm{~mm}$., and $9.5 \mathrm{~mm}$.

I am indebted to Dr. B. M. Allen for material to supplement certain stages in my own series.

The earlier part of the work unfortunately was undertaken with very inadequate material and resulted in the erroneous conclusion that the body closely associated during its development with the ultimobranchial body was a derivative of the fifth visceral pouch instead of the fourth. In the meantime there appeared the work of Shaner ${ }^{2}$ whose excellent models, especially of a 9.5- $\mathrm{mm}$. Chrysemys picta, leave no doubt as to the origin of the body in question. While a corresponding stage is lacking in my own material, I have a somewhat older specimen of Chelydra which proves the correctness of Shaner's results.

\section{THE VISCERAL POUCHES}

The account of the earlier stages in the development of the visceral pouches is based upon embryos of Chelydra and of Chrysemys. The conditions in the two genera are essentially similar, and selection is made from one or the other accordingly

${ }^{2} R$. F. Shaner, The development of the pharynx and aortic arches of the turtle, with a note on the fifth pulmonary arches of mammals. Am. Jour. Anat., Nov., 1921. 
as the more favorable stages are at hand to illustrate the successive steps in the developmental processes. For the later stages a number of specimens of Trionyx also are available. As in lizards, the first gill pouch does not give rise to any parts of the organs under consideration and may therefore be omitted from further reference in this connection.

In an embryo Chrysemys of $4 \mathrm{~mm}$. the first three visceral pouches are clearly differentiated. Just behind the third pouch is a fourth conspicuous evagination from the lateral pharyngeal wall. In form this diverticulum is more rounded than the preceding pouches. Its lateral wall is flattened and has rather broad contact with the ectodermal epithelium; and on its dorsal, ventral, and posterior walls constrictions occur in the sections by which the limits between the diverticulum and the pharyngeal wall proper appear clearly defined, but anteriorly these limits may be recognized only in a general way. The size and form of this evagination readily distinguish it from the typical visceral pouch and in its walls appear no differentiations that might indicate, as such, the developing fourth and fifth visceral pouches or the ultimobranchial diverticulum. In this specimen the first pair of the associated aortic arches is complete, but the second and third pairs are visible in their dorsal portions only.

A somewhat more advanced condition is shown in a $5-\mathrm{mm}$. Chelydra (fig. 1). The first three pouches have increased in depth. The first and second are already perforate and the third is nearly so. The second aortic arches are conspicuous, but reach only about half way to the ventral aorta. The third arches are now complete, as are also a very slender pair of fourth arches.

The diverticulum behind the third pouch has grown very considerably and two distinct areas or divisions in its wall are now discernible: an anterior larger part which is elongated in the dorsoventral direction, parallel with the third visceral pouch, and a second smaller part which appears as a diverticulum from the first, pushing out from its posterior wall. The former is in close contact with the ectoderm nearly throughout its length; and on its inner surface, along this line of contact, it presents a conspicuous furrow. In the light of subsequent stages, the 
larger of these two secondary diverticula represents the developing fourth visceral pouch; the smaller one represents an early stage in the differentiation of the diverticulum destined to give rise to the ultimobranchial body. A fifth pouch cannot as yet be positively identified (fig. 1, V, p. 5?), though potentially present.

At this stage there is on each side, between the pharynx proper and the diverticulum just mentioned, a slender blood vessel which inosculates with both the fourth aortic arch and the aortic root; it ends at the boundary line-between the fourth visceral pouch and the ultimobranchial diverticulum. This vessel is shown by later stages to be the fifth aortic arch.

The next available specimen is an embryo Chrysemys of 6.5 mm. (figs. 2, 3, and 13). In this embryo the fourth gill pouch also is perforate. The first three pouches, except for an increase in size, reveal no new features requiring comment. The pharyngeal outpouching, which in the preceding developmental stages embodied in one the fourth and fifth pouches and the ultimobranchial diverticulum, is now for the first time distinctly differentiated into its three component parts. Furthermore, the fifth visceral arch has arisen, interposing itself so as to separate the fourth pouch anteriorly from the other two components of the original vesicle. At its pharyngeal end the fourth pouch is broadly continuous with the remaining portion of the vesicle. The latter now consists largely of the ultimobranchial diverticulum, the fifth pouch appearing to be merely an anterior, somewhat laterally projecting, secondary outgrowth. The complex of diverticula as a whole has been constricted from the pharynx so as to open into it through a short but still relatively wide passage formed by the confluence of the mouth of the fourth pouch with a very short common opening of the fifth pouch and the ultimobranchial diverticulum. The ultimobranchial pocket has a depth equal to about two-thirds the dorsoventral extent of the fourth pouch. It is somewhat elliptical, flattened lateromedially, and its walls are thick. The fifth pouch is small and that of the left side is developmentally more advanced than its fellow. While the fifth pouch, as before remarked, 
appears to be a secondary diverticulum from the ultimobranchial pocket, this is evidently the result of the early differentiation of the ultimobranchial vesicle, involving as it does a relatively large area on the primary pharyngeal outpouching, one in which the diminutive fifth pouch is unable, as it were, to express itself until at a somewhat later stage. The short common passage or stalk previously referred to, by which the fifth pouch and the ultimobranchial diverticulum join the fourth pouch in opening into the pharyngeal cavity, evidently represents originally a portion of the pharyngeal wall proper, and the relations existing are consequently of secondary nature. The rudimentary fifth pouch had been carried bodily out from the pharyn $x$ by the ultimobranchial evagination.

In the fifth visceral arch at this stage there is a complete aortic arch, which, about one-fifth of its distance from the dorsal aorta, gives off a more slender posterior branch, the sixth aortic arch; this, after making a loop about the fifth visceral pouch, rejoins the fifth arch. The sixth aortic arch of the right side is incomplete ventrally. The sixth aortic arch lies in the angle formed by the ultimobranchial diverticulum and the fifth pouch, the former being wholly medial to the vessel.

The fifth visceral pouch is in intimate contact with the ectoderm along its lateral edge. The ultimobranchial outgrowth nowhere touches the outer germ layer; its basal or proximal end is opposite the origin of the trachea, and the distal end is directed ventrally, parallel to the long axis of the fourth pouch.

In an embryo Chelydra of $7.5 \mathrm{~mm}$. and one of $9 \mathrm{~mm}$., the second and third pouches are still perforate, and in the latter specimen the fourth also is open. The pouches are much flattened anteroposteriorly and their dorsoventral axes have increased considerably in length. Because of the greatly narrowed ectodermal and entodermal connections, the dorsal and ventral portions of the second and third pouches appear in the sections as closed vesicles and the posterior wall of the dorsal extensions of these two pouches is now much thicker than the anterior wall. A more pronounced advance, however, is apparent in connection with the posterior complex of diverticula (figs. 4 and 5) where the 
fifth visceral arch, by its increase in depth, has separated the fourth visceral pouch more widely from the associated fifth pouch and ultimobranchial body. Also a second process of separation, proceeding simultaneously, is well under way, namely, the pinching off of the complex as a whole from the pharynx by the constriction of the common connecting stalk.

The fifth visceral pouches in these stages appear to attain their full development as such. In the larger specimens the right pouch is distinctly larger than the left, but in the smaller the two are of about equal size. Contact with the ectoderm is still maintained, but is more restricted than in the preceding stage. On each side of the body a neck-like stalk connects the fifth pouch with the ultimobranchial diverticulum. While, as remarked, the right pouch in the larger specimen of Chelydra is larger than the left, other specimens of this genus as well as of Chrysemys indicate that there is considerable variation in the comparative size of right and left pouches in different embryos. In the 9-mm. Chelydra the long, or dorsoventral axis, of the larger right pouch is about one-fourth that of the fourth visceral pouch.

The ultimobranchial body, beyond an increase in length and the clearer demarcation noted above, exhibits no important changes.

A notable feature in connection with the aortic arches at this stage is that the middle segment of the fifth arch, or that which forms the anterior limb of the loop, is exceeded in caliber, although slightly, by the posterior limb or that which represents the $s$ xth aortic arch. In another embryo Chelydra of $7.5 \mathrm{~mm}$., which in other respects is in a corresponding stage of development, the sixth aortic arch is already much larger than the fifth. In both specimens the pulmonary artery is now present as a branch of the sixth arch immediately above its junction with the fifth.

In a $9.5-\mathrm{mm}$. Chelydra, the second visceral pouch has lost its connection with the eetoderm; its dorsal portion shows a thickening of the epithelium which probably represents a transitory thymus bud, disappearing with the closure of the pouch. The ectodermal duct is a very much attenuated tube, but has a longitudinal cellular ridge projecting into its lumen from its medial wall (fig. 6). 
The third pouch also has severed its connection with the ectoderm and appears as an elongate, rather thick-walled longitudinal vesicle, extending from the tip of the anterior horn of the hyoid to a point opposite the middle of the posterior horn. The cephalic end of the pouch lies medial to the anterior horn, while the caudal end is lateral to the posterior horn. In length, the left pouch extends through nineteen sections $(285 \mu)$, the right through seventeen sections $(255 \mu)$. A very short pharyngeal stalk or entodermal duct, now closed, extends through the sixth to the eighth sections, inclusive, on the left and through the fifth to the seventh on the right. On each side the pouch is crescentic in cross-section (fig. 7), but anterior to the pharyngeal stalk the convex side is ventral while posterior to the stalk it is dorsal. The walls of the vesicle are generally of uniform thickness anterior to the pharyngeal attachment, but here and there the epithelium shows a tendency to fold, and at the anterior end solid buds of cells have formed; likewise on the ventrolateral surface of the vesicular wall there is a conspicuous ridge, formed evidently by local proliferation, extending from the anterior end of the pouch to its pharyngeal stalk. This ridge is symmetrical on the two sides of the body and, together with the cell proliferation noted on the anterior wall of the pouch, is apparently the beginning of thymus formation. Caudal to the pharyngeal stalk the ventral wall of the pouch is decidedly thicker than the dorsal, and from the dorsolateral wall there projects outwardly a solid cellular peg which evidently represents the point of separation from the ectoderm.

The fourth visceral pouch is detached and far removed from the surface epithelium. It is a small, more or less rounded vesicle, with irregular surface contour and with slit-like cavity. The ventrolateral wall is thickened, especially in its middle portion. The entire vesicle extends through eight sections $(120 \mu)$. It is attached to the ultimobranchial vesicle by a short, narrow stalk which contains the last traces of a cavity. The two sides of the body exhibit practically identical conditions. A differentiation into thymus and parathyreoid portions is not with certainty recognizable. 
Regarding the fifth pouch, the gap in my series between the present stage and the preceding is too great to indicate what has taken place in the meantime. In the present specimen there is a small mass of cells lying between the fourth pouch and the ultimobranchial vesicle, just behind the point of connection between these two; the mass has the appearance of undergoing degeneration, and it is possible that it represents the remnants of the fifth pouch.

The ultimobranchial body of the left side is typical for the stage under consideration - an elongate tube lying lateral to and parallel with the trachea. It is largest in its middle portion and tapers more or less towards the ends. The walls are of uniform thickness and the enclosed cavity is sharply defined. Proximally, the vesicle narrows rapidly in approaching its connection with the fourth pouch, and from this point on it becomes merely an attenuated pedicle connecting the two vesicles as a unit with the pharynx. Close to the entodermal wall this stalk is about to be constricted off, but within it a pinhole cavity is visible.

The next step is based upon a $10.5-\mathrm{mm}$. Chelydra, a $6-\mathrm{mm}$. Chrysemys, and a 9-mm. Trionyx. In Chelydra the third visceral pouch has been transformed into an elongate, compact mass. The anterior two-thirds is considerably larger than the caudal third and it contains a vestige of the original cavity, around which the innermost cells retain in slight degree their epithelial character. Anteriorly, and to a less extent in other parts, the mass sends out a number of solid mounds of cells, which give it a somewhat lobular appearance. The smaller caudal mass is a continuation of the medial part only of the anterior mass. It is cylindrical and, like the anterior part, contains a trace of the earlier lumen. In brief, the conditions just described simply mean that the third pouch at this stage shows definite differentiation into an anterior thymus body and a posterior parathyreoid body, representing, respectively, dorsal and ventral portions of the original visceral pouch. In the specimens of Chrysemys and of Trionyx the third pouch is developmentally slightly more advanced, but otherwise it presents conditions similar to those just described. 
The fourth pouch has by this time also developed into an almost entirely solid body, club-shaped in form, the tapering end directed forward and slightly marked off from the posterior part, as if it represented a rudimentary thymus. The pouch extends through eleven sections $(175 \mu)$, the three middle sections alone containing evidence of the former cavity. The caudal end is in close proximity to the ultimobranchial body from which it apparently has just become separated. The ultimobranchial vesicle of the left side (fig. 9) shows a very considerable increase in size and is expanded so as to be nearly circular in cross-section, but it has the same smooth-walled appearance as in preceding stages. In greater part the wall shows three or four tiers of nuclei, but in some places there is only one. Its anterior extremity bears a small cellular peg which evidently fixes the point of separation of the fourth visceral pouch.

The conditions of the right side in this embryo deserve notice in that there apparently is complete absence of the ultimobranchial body; it is the only instance in my series where this occurs. A slender cellular stalk, similar to that of the left side, extends from the pharynx to the fourth pouch, to which it furnishes a short pedicle, and then ends only three sections beyond this point, without discernible evidence of an ultimobranchial vesicle. However, the limits between what constitutes the ultimobranchial vesicle proper and the part which represents more or less of the drawnout portion of the pharyngeal wall cannot in any case be exactly determined, and therefore, in view of the conditions found in subsequent stages relative to the point of connection between the fourth pouch and the ultimobranchial vesicle, it is still possible that the latter is potentially present, though in a very rudimentary form, in the distal portion of the entodermal stalk.

The embryo Chrysemys, in corresponding stage of development, shows a condition of the branchial derivatives similar to that of Chelydra, with minor variations. The second visceral pouches have identical tube-like extensions (ectodermal ducts), but these are without cellular buds or areas of proliferation. The third pouch is somewhat more advanced. Its anterior portion is a solid mass of more or less lobular appearance, the original 
cavity having been obliterated as far back as the pharyngeal stalk. Caudal to this point the pouch has still a conspicuous lumen, but it becomes solid again in the posterior half. In its entirety the third pouch does not exhibit such clear conditions as in Chelydra, and it is uncertain from available material whether or not any particular portion of its wall may be considered as initiating the process of organ formation, such as appears to be the case in Chelydra. In sections through the region of its pharyngeal connection the vesicle has the same crescentic form as in Chelydra and, on one side at least, the lateral wall is noticeably thicker, but, because of the solidification of the pouch anteriorly, the original relation or the significance of this thickening cannot be determined. The fourth visceral pouch has a broader connection with the ultimobranchial vesicle and the latter is well developed on both sides of the body, although that of the left is by far the larger.

In another $10.5-\mathrm{mm}$. Chelydra a variation in connection with the fourth pouch and the ultimobranchial body should be noted. On the right side a relatively large ultimobranchial vesicle is present. It is spindle-shaped and extends through fifteen sections, having a diameter in its widest part of approximately one and a half times that of the trachea; its walls are thick and the lumen clear-cut. Its anterior end lies just outside the mesenchymal coat of the oesophagus and reaches the level of the parathyreoid III. With this ultimobranchial body the fourth pouch derivative as yet maintains a slender cellular connection (fig. 11), but, instead of being situated at the anterior end of the vesicle, where it is found in most cases, it here lies at the posterior end. How this relation may have been brought about is not evident, but it possibly may be accounted for by assuming that, after the ultimobranchial vesicle had separated from the pharynx, that portion of its neck proximal to the junction of the fourth pouch, in which the limits of the ultimobranchial vesicle proper are indefinite, continued to develop, while the part distal to the junction suffered regression or had, perhaps, been rudimentary from the outset. On the left side of the body the relations are of the usual kind. The ultimobranchial 
vesicle extends through twenty-five sections; while its walls are thicker than in the preceding embryo-indicative, as a rule, of an earlier stage - it shows a more advanced condition in that they bear a number of secondary evaginations of various sizes as well as numerous solid protrusions or sprouts. Both kinds are especially large and conspicuous about the anterior end of the vesicle, while minor ones occur somewhat distal to its middle section.

In a $6-\mathrm{mm}$. Chrysemys, representing approximately the same developmental stage as the foregoing embryo, a further variation with respect to the fourth visceral pouch and the ultimobranchial vesicle occurs. The left fourth pouch has been converted into a compact cellular mass with even surface contour and without trace of lumen, and is attached in the usual manner by a solid stalk near the anterior end of the ultimobranchial vesicle. The last named, except for its smaller size, is similar to that of the 10.5-mm. Chelydra. The right fourth pouch derivative is much longer than the left $(330 \mu$ as against 240$)$ and its middle portion is expanded into a vesicle of nearly the same diameter as the ultimobranchial vesicle itself (fig. 18), into which it opens by a passage extending through five sections; and the ultimobranchial vesicle is unusually large for this side, being somewhat more than half the length and width of the left one.

A $9-\mathrm{mm}$. Trionyx is the youngest specimen of this genus $\mathrm{n}$ my possession. In general development it agrees well with the preceding specimen of Chrysemys. The derivatives of the third visceral pouch reveal no noteworthy differences from those of corresponding stages of Chrysemys or Chelydra; but the fourth pouch derivative and the ultimobranchial vesicle show distinct variations from the conditions in those genera. On the left side the two bodies in question have the usual position relative to each other and have a cellular connection, but in form they are of somewhat different type. The ultimobranchial vesicle is much more advanced in development than that of either Chrysemys or Chelydra of corresponding age in that a large portion of it has already been transformed into solid cord-like cell-clusters, while elsewhere it bears spherical, hollow outgrowths from its 
walls. These growth processes have been most active in the anterior portion of the vesicle, but are present in varying degree throughout its length. In the midst of the proliferating mass, however, the walls are sufficiently intact to show what had been the general form and size of the vesicle at the height of its development, and in these respects it bears closer resemblance to Chrysemys than to Chelydra, as it evidently attains neither the large size nor the thin-walled condition of the latter. The right ultimobranchial vesicle is a thin-walled tubular structure whose epithelium consists of one or two layers of flattened, loosely arranged cells, evidently in process of retrogression. The fourth pouch derivatives are both characterized by a highly vesicular condition, quite in contrast to the usual solid cellular mass in corresponding stages of the other two genera, but a tendency toward which was seen in the 6-mm. Chrysemys. The walls of these vesicles retain, in part, their early sharply defined epithelial form, in part contain foldings and thickenings due to cell proliferation. The tendency of the fourth pouch derivative in Trionyx to assume a vesicular form occurs in later stages and appears to be a distinctive feature of this genus.

Figure 14 represents a wax-plate reconstruction of the branchial derivatives of the left side of an embryo Chelydra of 9.5$\mathrm{mm}$. carapace length. The thymus and the parathyreoid III maintain their earlier linear arrangement and partly encircle the carotid artery. The fourth pouch derivative, still attached to the ultimobranchial vesicle, lies medial to and occupies the interval between the systemic and the pulmonary arch (the latter omitted in the model). The ultimobranchial vesicle has attained relatively enormous proportions, the maximal in my series, having a diameter approximately one-half that of the oesophagus. Only on its anterior and anterodorsal surfaces do the sections reveal cellular outgrowths and extensions from the otherwise smooth wall of the vesicle. Its fellow of the opposite side is relatively insignificant and the fourth pouch of this side is also much inferior in size and is furthermore completely detached from the ultimobranchial body. 
An embryo Chrysemys and one of Trionyx of 8-mm. and 9-mm. carapace length, respectively, show a general developmental stage corresponding to the preceding embryo Chelydra. In Chrysemys the derivaties of the third visceral pouch together form a more or less rounded three-lobed mass, partly encircling the carotid artery from the dorsal side (on the left), or from the medial side (on the right). Two larger anterior lobes constitute the thymus, while the third lobe, smaller and situated posteriorly, is the parathyreoid body, the two still having cellular continuity. The parathyreoid here is lateral to the thymus instead of caudal, as in Chelydra, possibly due to a growth or shifting caudad of the thymus. The fourth pouch derivative and the ultimobranchial body have the same relative positions as in Chelydra. The latter body here likewise attains its maximal size as a vesicle, but is relatively and absolutely much smaller and has the general form of a cylindrical tube. The vesicle of the opposite side is rudimentary.

In Trionyx the thymus and its associated parathyreoid III have the same tandem arrangement as in Chelydra. The fourth pouch derivative may lie against the medial side of the systemic arch, or between this vessel and the pulmonary arch, opposite the bifurcation of the trachea. On both sides of the body the walls of this derivative are somewhat thickened, but maintain an even epithelial arrangement about a relatively large central cavity, as in the earlier 9-mm. stage. The right ultimobranchial vesicle is very rudimentary; the left one is even smaller than that of Chrysemys, and is profusely covered with cellular excrescences, especially in its posterior portion.

\section{LATER DIFFERENTIATION}

In the well-advanced embryos just described the various branchial derivatives have been identifiable, largely or entirely by their respective histories and place relations. Actual structural differences in the thymus, the parathyreoids, and the fourth pouch derivatives are, even in the oldest of these embryos, wanting or at least uncertain in the sections. The form of the dominant ultimobranchial vesicle renders this organ unmistak- 
able, but, especially in Trionyx, on the side where the vesicle is rudimentary, the fourth pouch derivative may at times assume a very similar form, so that the two may be distinguished with certainty chiefly by their relative position.

The following account is based upon an embryo Chrysemys of 11-mm. carapace length, one of 15-mm. carapace length, and one at hatching; two embryos of Trionyx of carapace length of 9 $\mathrm{mm}$. and $13 \mathrm{~mm}$., respectively, and two of Chelydra of carapace length of $15 \mathrm{~mm}$. and $16 \mathrm{~mm}$., respectively.

The thymus and parathyreoid bodies are now readily distinguishable from each other, both as to structure and staining properties. The thymus has taken on the characteristic lymphoid appearance and stains deeply. The parathyreoid, on the other hand, exhibits its usual cord-like, epithelial cell masses, with invasions among them of mesenchymal tissue; these features together with the relatively greater amount of eytoplasm in the cells and their less deeply staining nuclei contrast this organ sharply with the thymus. In regard to the relation of the thymus to the carotid artery, Chrysemys and Chelydra are in accord and differ from Trionyx. In the former two the artery is situated laterally, having changed from an earlier, more ventral position. In Trionyx the vessel courses along the medial surface of the gland, but in an earlier stage it was near the ventral surface. In both groups, if a large series were examined, a considerable amount of variation would no doubt be found in the degree of rotation of the thymus about the artery. The parathyreoids are apparently also quite variable, within certain limits, as to their position in the later stages. In Trionyx, where they are somewhat less advanced than in the other two forms, the organ of the left side lies on the ventromedial, while that of the right lies on the ventrolateral surface of the thymus, slightly anterior to its caudal end. In Chrysemys the parathyreoid III is on the medial side of the thymus, more or less deeply imbedded and separated from the carotid by a considerable mass of thymous tissue; in Chelydra its situation is lateral or dorsolateral upon the thymus adjacent to the carotid in the younger specimen of this genus, but in the older it is found to have been shifted somewhat and 
has become partly imbedded in the thymus (figs. 21, 22). Regarding the growth changes in the parathyreoid in these later stages my series is too small to furnish definite answer, but from measurements in Chrysemys it seems that, while the thymus increases greatly, the parathyreoid III suffers a cessation or retardation of growth in size between the stage of $15-\mathrm{mm}$. or 16-mm. carapace length and that of hatching.

In the embryo Chrysemys of 11-mm. carapace length the fourth pouch derivative shows structural and staining characteristics identical with those of the parathyreoid III. It lies somewhat isolated from the derivatives of the third pouch and I find no evidence of thymus tissue in connection. with it on either side of the body. The derivative of the fourth pouch, therefore, at least from the evidence in this case, is a parathyreoid body only, but it is quite possible that a thymus sometimes is developed also. In the present specimen the parathyreoid IV has suffered little if any change in position from that of this derivative of earlier stages, being situated upon the dorsolateral surface and slightly caudal to the anterior end of the ultimobranchial body; lateral to it appears the posterior tip of the thymus III. The parathyreoid IV of the right side, which is somewhat larger than its fellow, still has the rudimentary ultimobranchial body attached to its ventral surface. As stated in connection with the 9-mm. Trionyx, the fourth pouch derivative was inclined to be more vesicular than in the other two genera during the early stages, and the same tendency appears in the older embryos now concerned. In the smaller of these (9-mm. c. l.) it has an appearance not unlike that of the ultimobranchial vesicle, but is smaller. The body of the right side especially is large and thinwalled (fig. 17) and caudally has developed three secondary out-pouchings from the main vesicle, giving to the whole still more the character of an ultimobranchial body. In the older embryo (13-mm. c. l.) the bladder form is even more pronounced, but here this feature may involve only a part of the entire organ. Thus, on the left side, the fourth pouch derivative consists of a ventromedial solid mass and a dorsolateral bladder-like portion in which the wall is extremely thin and apparently in process of 
disintegration, while on the right side there is a single much enlarged cyst in which the dorsal and posterior walls alone bear thickenings or proliferating cell masses (fig. 19). The walls of these bladder-like expansions of the fourth pouch derivative at this stage do not, as a rule, possess the clear-cut epithelial arrangement of their cells nor the smooth even contour of their inner and outer surfaces which characterized the earlier stages. The cells are notably crowded and jumbled, with here and there dissociated cells intruding into the central cavity.

But while it appears that in Trionyx the fourth pouch derivative is characterized by the tendency to cyst formation from its early stages and upward, a similar condition, and one which was not foreshadowed in the last-described stage $(9.5-\mathrm{mm}$. c. 1.) of this genus, occurs in the Chelydra embryos of $15-\mathrm{mm}$. and 16-mm. carapace length (figs. 20, 23). The greatest development of the vesicular portion is found in the smaller of the two embryos, where it not only exceeds any of the corresponding vesicles in Trionyx, but approaches closely the size of the larger ultimobranchial vesicle in the same embryo. It will be observed from the figures that only a part of the fourth pouch derivative is involved in the cyst, the whole being, as in Trionyx, composed of a glandular and a vesicular part. In the younger embryo the glandular part lies upon the ventrolateral wall of the bladder portion, while in the older specimen it lies upon the ventromedial and the dorsolateral surface, of right and left sides, respectively. At some points the cyst wall has reached a thinness bordering on the breaking-point, where the cells form a single layer and assume a mesothelial appearance. In all cases the cyst portion has cellular continuity with the glandular body, although, as in figure 20 , the connection may at times be reduced to a very slender stalk.

The significance of the vesicular portion of the parathyreoid IV is not clear. As to its origin, however, it seems quite certain, from the conditions observed in Trionyx, that it is a part of the original cavity and wall of the fourth visceral pouch. The question will suggest itself whether it may represent a portion of the ultimobranchial vesicle which has separated, along with the 
fourth pouch, and later manifests itself in the tendency to cyst formation that is so characteristic of that body. Again, it might conceivably be interpreted as a vestige of some other derivative of the fourth pouch, such as a thymus. Opposed to the first of these views, if not entirely to the second, is the fact that in both embryos of Chelydra (15-mm. and $16-\mathrm{mm}$. c. l.), although on the right side only, an exactly similar vesicle occurs in connection with the parathyreoid III (fig. 21). In the younger specimen the cyst is largely surrounded by thymous tissue. In the later series of Chrysemys the parathyreoid IV gives no evidence of cyst formation, but in an embryo of $15-\mathrm{mm}$. carapace length parathyreoid III contains an excentric cavity of moderate size whose wall is a single layer of cells, sharply differentiated from the surrounding tissue. In an embryo at hatching there is what appears to be a trace of such a cavity in the corresponding gland; in the parathyreoid IV evidence of such condition is doubtful.

The ultimobranchial body in all of the later stages mentioned, except that of hatching, shows merely a continuation of the process of reduction of the vesicle, begun in some of the younger embryos. In the present older specimens the vesicle is either completely broken down into a mass of diminutive vesicles and solid cell masses more or less spherical or cord-like in form, as in Chelydra of 16-mm. earapace length (fig. 23); or the main cyst is studded with sprouts and is extensively broken up and reduced in size, as in an embryo Chrysemys of 11-mm. carapace length. The process of reduction and transformation of the original vesicle apparently takes place, chiefly, by two methods: by the formation through evagination and separation (and perhaps also simply by constriction) from the main body, of smaller cysts of varying sizes and forms, and by the outgrowth and detachment from its wall of solid cellular sprouts. In the sprouts the cells at first have a radial or epithelial arrangement in section, and while in some of them an actual lumen may appear, in others such is seemingly not the case. The secondary vesicles undergo further reduction in the same manner as the parent structure. In the older specimen of Chelydra (16-mm. c. 1.) 
and in Trionyx of 13-mm. carapace length the ultimobranchial body assumes a structure resembling that of the thyreoid in the same specimens, but, nevertheless, distinct and readily distinguishable from it by the complete absence of colloid within the vesicles, by the comparatively small number of such vesicles or tubules, as well as by their irregular form, thicker walls, and often ill-defined lumina. A rudimentary right ultmobranchial body is present in all of the later stages described and it undergoes parallel differentiation with that of its much larger fellow.

In Chrysemys at the time of hatching the ultimobranchial body has assumed an appearance very much like that of the parathyreoid of the same embryo, namely, a rather lightly staining lymphoid structure in which traces of the earlier arrangement and grouping of the cells are clearly recognizable only in a few places. The position of the body remains the same. Deeply imbedded within the left ultimobranchial body lies the parathyreoid IV, which, however, is surrounded by a thin connective-tissue capsule of its own. The ultimobranchial body of the right side consists of a small mass of tissue on the medial side of and partly investing the parathyreoid IV; in structural differentiation it is like its fellow of the opposite side.

\section{SUMMARY}

1. The development of the branchial derivatives was studied in turtles of the genera Chelydra, Chrysemys, and Trionyx.

2. The persisting thymus arises from the dorsal portion of the third visceral pouch. In the corresponding portion of the second visceral pouch there is a cellular bud which is interpreted as a rudimentary, transitory thymus.

3. The ventral portion of the third visceral pouch gives origin to a persisting parathyreoid.

4. The fourth visceral pouch gives rise to a persisting parathyreoid, but so far as available material indicates there is no indisputable evidence that a persisting thymus arises from this pouch. A rudimentary thymus which is transitory probably occurs. 
5. The fifth visceral pouch seems to disappear soon after it attains its greatest development, which in Chelydra was found to be in embryos of $7.5 \mathrm{~mm}$. to $9 \mathrm{~mm}$. greatest length.

6. A conspicuous ultimobranchial vesicle is usually present on each side in the early stages, but the one on the right, as a rule, soon reaches limitations in growth and becomes greatly exceeded in size by its fellow of the opposite side. The body on the right may apparently at times be wholly lacking. Where both are present, they appear to undergo parallel differentiation, at least up to the time of hatching. The relatively huge dimensions sometimes attained by the dominant ultimobranchial vesicle is a striking feature.

7. In turtles the fourth and fifth visceral pouches and the ultimobranchial diverticulum originate in a single conspicuous evagination from the lateral pharyngeal wall. In this evagination the fourth pouch is the first to be differentiated; next appears the ultimobranchial diverticulum, and lastly the fifth pouch may be distinguished, which is closely associated with the ultimobranchial diverticulum and is very small.

8. The fourth pouch and the ultimobranchial diverticulum become separated as a unit from the pharynx, but remain connected with each other until a comparatively late stage in their development.

9. The fourth pouch in subsequent development exhibits more or less of a tendency toward cyst formation. This seems to be manifested earlier in Trionyx than in the other two genera studied; but in later stages very large cysts, relatively speaking, were found in connection with the fourth pouch in Chelydra. In Chelydra such tendency was observed also in connection with the parathyreoid III. The significance of the cysts is not clear.

10. At the time of hatching the thymus is a rather voluminous body of oblong shape, and parathyreoid III is a relatively small rounded body which is more or less deeply imbedded in the caudal portion of the former gland.

11. Parathyreoid IV, similar in size and shape to the parathyreoid III, is usually found in close association with or partly 
or wholly imbedded in the ultimobranchial body (on the left side); or (on the right side, where the ultimobranchial body is rudimentary) it may be adjacent to parathyreoid III, and with it becomes partly surrounded by thymous tissue; or it may lie further caudad in association with the ultimobranchial body.

12. The ultimobranchial body, by the time of hatching, has been transformed almost completely into a lymphoid organ, resembling the parathyreoids at this stage. It is in no way associated with the thyreoid.

\section{BIBLIOGRAPHY}

Bemmelen, J. F. van 1893 Ueber die Entwicklung der Kiementaschen und der Aortenbogen bei den Seeschildkröten, untersucht an Embryonen von Chelonia viridis. Anat. Anz., Bd. 8.

1886 Die Visceraltaschen und Aortenbogen bei Reptilien und Vögeln. Zool. Anz., Bd. 9.

JoHNson, C. E. 1918 The origin of the ultimobranchial body and its relation to the fifth pouch in birds. Jour. Morph., v. 31.

Lressner, F. 1888 Ein Beitrag zur Kenntnis der Kiemenspalten und ihrer Anlagen bei amnioten Wirbelthieren. Morph. Jahrb., 13.

MAURER, F. 1899 Die Schildrüse, Thymus und andere Sehlundspaltenderivate bei der Eidechse. Morph. Tahrb., 27.

Medron, P. DE 1886 Recherches sur le développement du thymus et de la glande thyreoïde. Dessertation, Geneve.

Peter, K. 1900-01 Mittheilungen zur Entwicklungsgeschichte der Eidechse. II. Die Schlundspalten und ihrer Anlage, Ausbildung und Bedeutung. Arch. f. mikr. Anat., Bd. 57.

Saint-Remy et Prenant 1903-04 Recherches sur le développement de dérivés branchiaux chez les Sauriens et les Ophidiens. Arch. de Biol., T. 20.

Verdun, P. 1898 Dérivés branchiaux chez les vertebrés supérieurs. Thése, Toulouse. 


\section{ABBREVIATIONS}

A.a., aortic arches

Ar.car., carotid artery

Ao.r., aortic root

$B r$. bronchus

D.ao, dorsal aorta

Oes., oesophagus

Par. III, IV, parathyreoids, derived

from the third and fourth pouches, respectively

$P h$, pharynx

$P h . d i v .$, pharyngeal diverticulum
S.a., systemic arch

$T h y$., thymus

$T h r .$, thyreoid

Tr., trachea

U.b., ultimobranchial vesicle or body

Vag., vagus nerve

V.a.5, fifth visceral arch

Ves., vesicular portion of parathyreoids

$V . p .2,3,4,5$, visceral pouches, second to fifth

\section{PLATE 1}

\section{EXPLANATION OF FIGURES}

1 Frontal section through the posterior pharyngeal region of an embryo Chelydra serpentina $5 \mathrm{~mm}$. long. $\times 80$.

2 Frontal section through the corresponding region of an embryo Chrysemys marginata $6.5 \mathrm{~mm}$. long, showing developing fifth visceral arch and the differentiated fourth and fifth visceral pouches. $\times 80$.

3 Same embryo as figure 2 , section taken farther ventrally, showing relation of fifth pouch to ultimobranchial vesicle. $\times 80$.

4 Frontal section from an embryo C. serpentina $7.5 \mathrm{~mm}$. long, passing through the main body of the ultimobranchial vesicle and showing also progressive development of the fifth visceral pouch. $\times 80$.

5 Frontal section from an embryo C. serpentina $9 \mathrm{~mm}$. long, showing connection between fourth viseeral pouch and ultimobranchial vesicle and also a further step in development of the fifth visceral pouch and corresponding visceral arch. $\times 80$. 
CHARLEA EUGENE JOHNSON
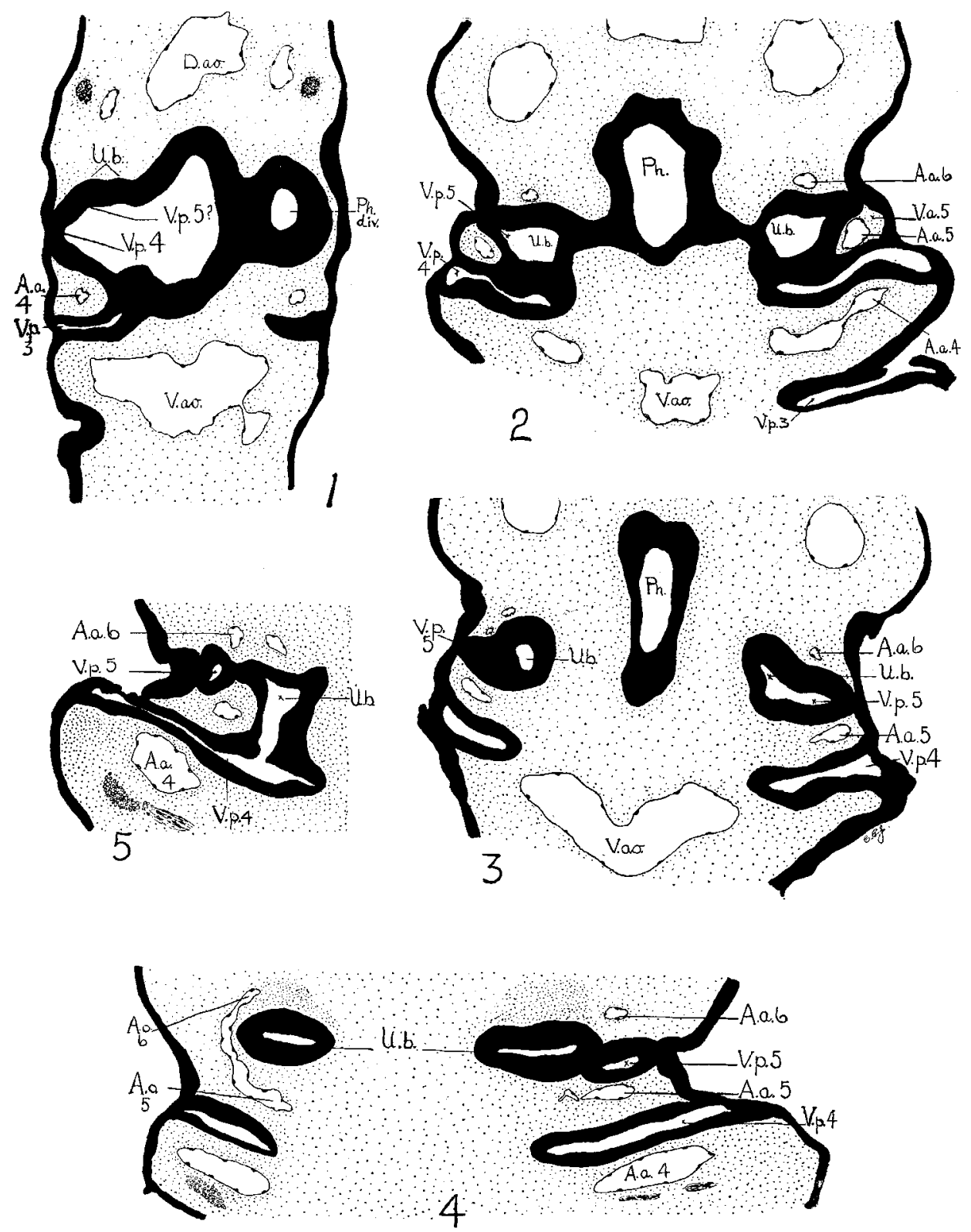


\section{PLATE 2}

\section{EXPLANATION OF FIGURES}

6 Transverse section through the ectodermal duct of the second visceral pouch in an embryo Chelydra $9.5 \mathrm{~mm}$. long. $\times 300$.

7 Section through the third visceral pouch of the same embryo as figure 6 , showing early step in the development of the thymus. $\times 230$.

8 Transverse section through the fourth pouch derivative of an embryo Chelydra with carapace $9.5 \mathrm{~mm}$. long. $\times 300$.

9 Transverse section through the left ultimobranchial vesicle of an embryo Chelydra $10.5 \mathrm{~mm}$. long. $\times 230$.

10 Transverse section through the developing thymus of the right side of an embryo Chelydra $10.5 \mathrm{~mm}$. long. $\times 230$.

11 Transverse section through the fourth pouch derivative and the ultimobranchial body of the right side of an embryo Chelydra $10.5 \mathrm{~mm}$. long. $\times 300$.

12 Transverse section through a part of the left lateral wall of the left ultimobranchial vesicle and attached fourth pouch derivative, from an embryo Chelydra with carapace $9.5 \mathrm{~mm}$. long. Same embryo as figure $8 . \times 300$. 


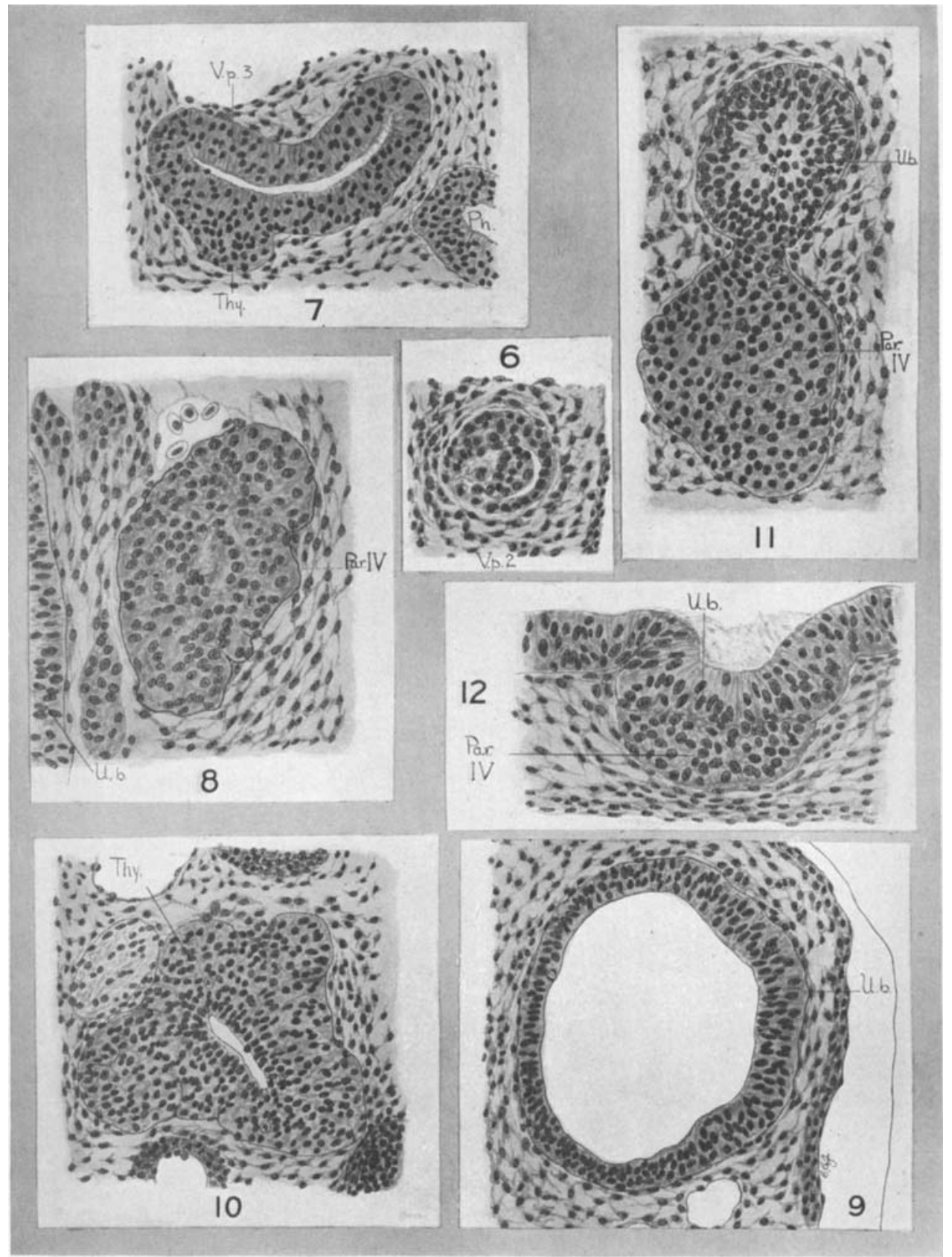




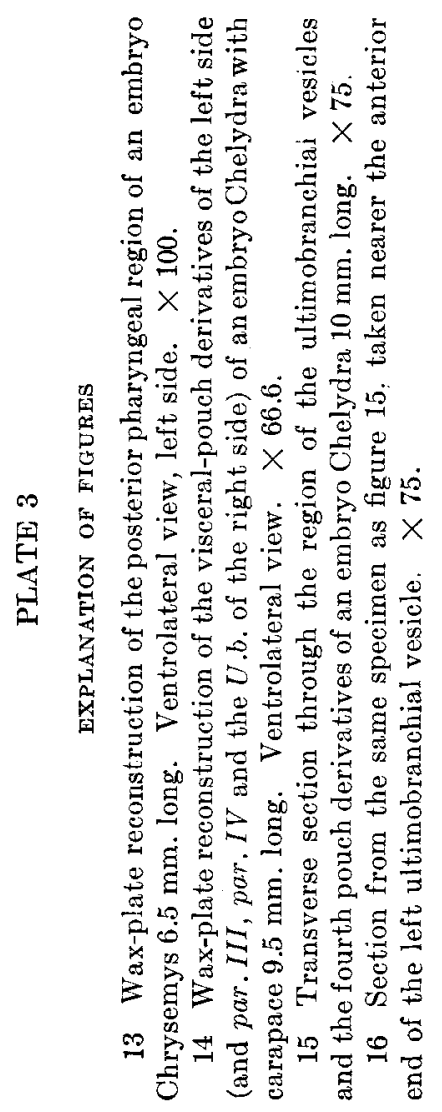




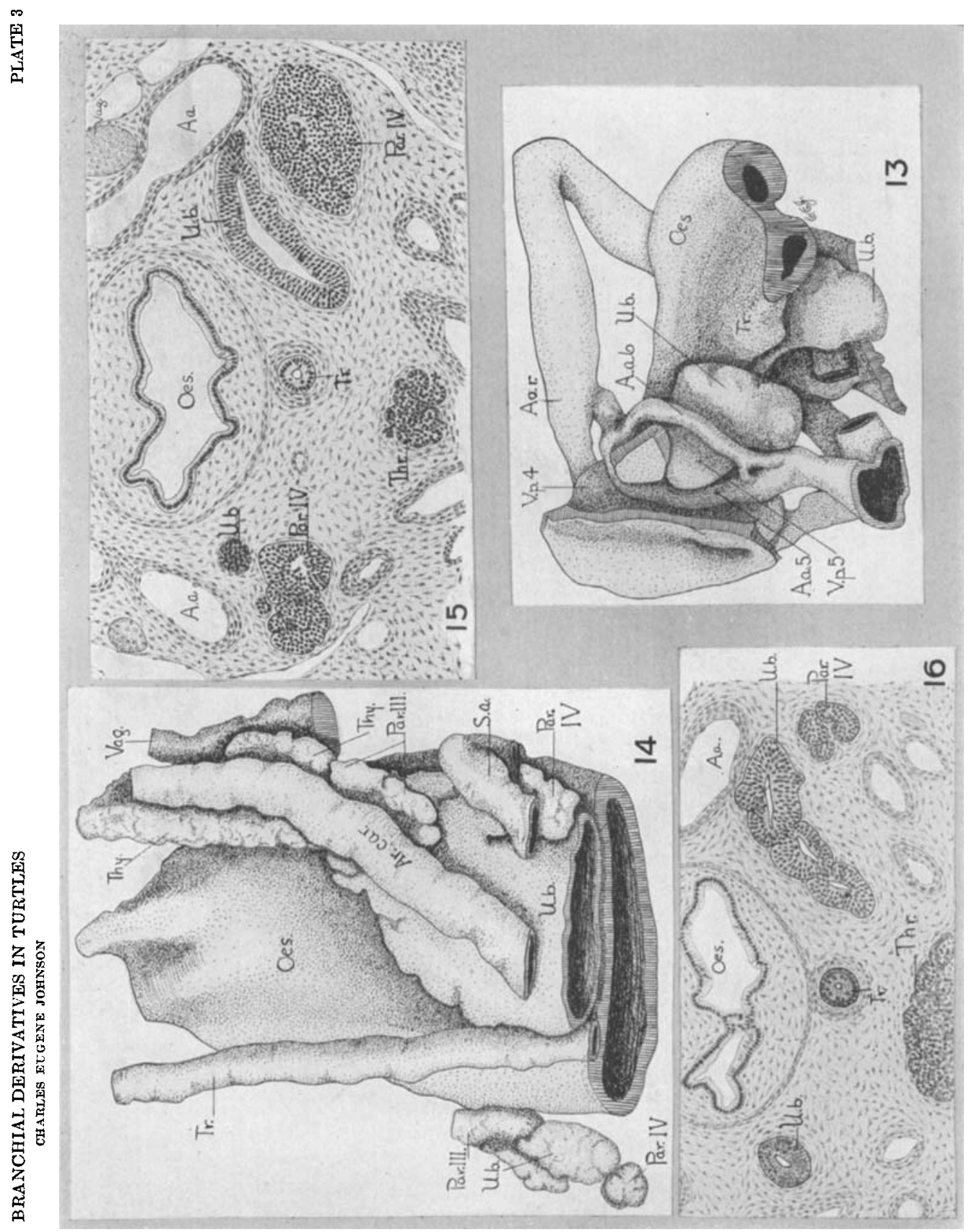




\section{PLATE 4}

\section{EXPLANATION OF FIGURES}

17 Transverse section through the fourth pouch derivative and the ultimobranchial vesicle of the right side of an embryo Trionyx sp. with carapace $9 \mathrm{~mm}$. long. $\times 230$.

18 Transverse section through the same structures of the right side of an embryo Chrysemys $6 \mathrm{~mm}$. long. $\times 230$.

19 Transverse section through the fourth pouch derivative of the right side of an embryo Trionyx with carapace $13 \mathrm{~mm}$. long. $\times 230$. 


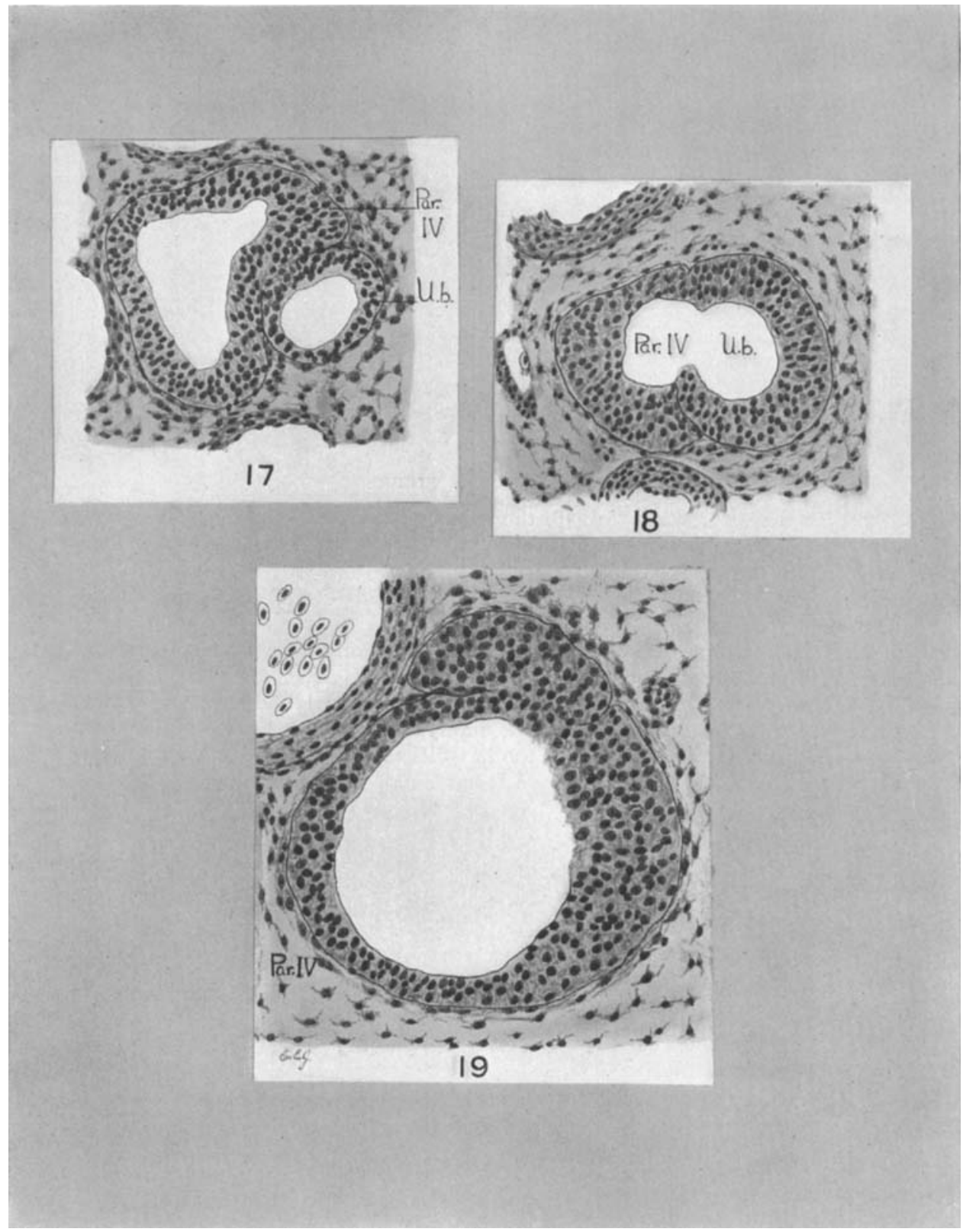




\section{PLATE 5}

\section{EXPLANATION OF FIGURES}

20 Transverse section through the parathyreoid IV and the caudal portion of the thymus of the right side of an embryo Chelydra with carapace $16 \mathrm{~mm}$. long. $\times 50$.

21 Same embryo. Section through parathyreoid III and the thymus of the right side. $\times 50$.

22 Same embryo. Section taken farther anteriorly than that of figure 21, showing thymus and parathyreoid III of left side. $\times 50$.

23 Transverse section through the ultimobranchial body and the parathyreoid IV of the left side; from same embryo as figures 20 to $22 . \times 75$.

24 Transverse section through the left ultimobranchial body and the parathyreoid IV of an embryo Chrysemys at hatching. $\times 50$. 


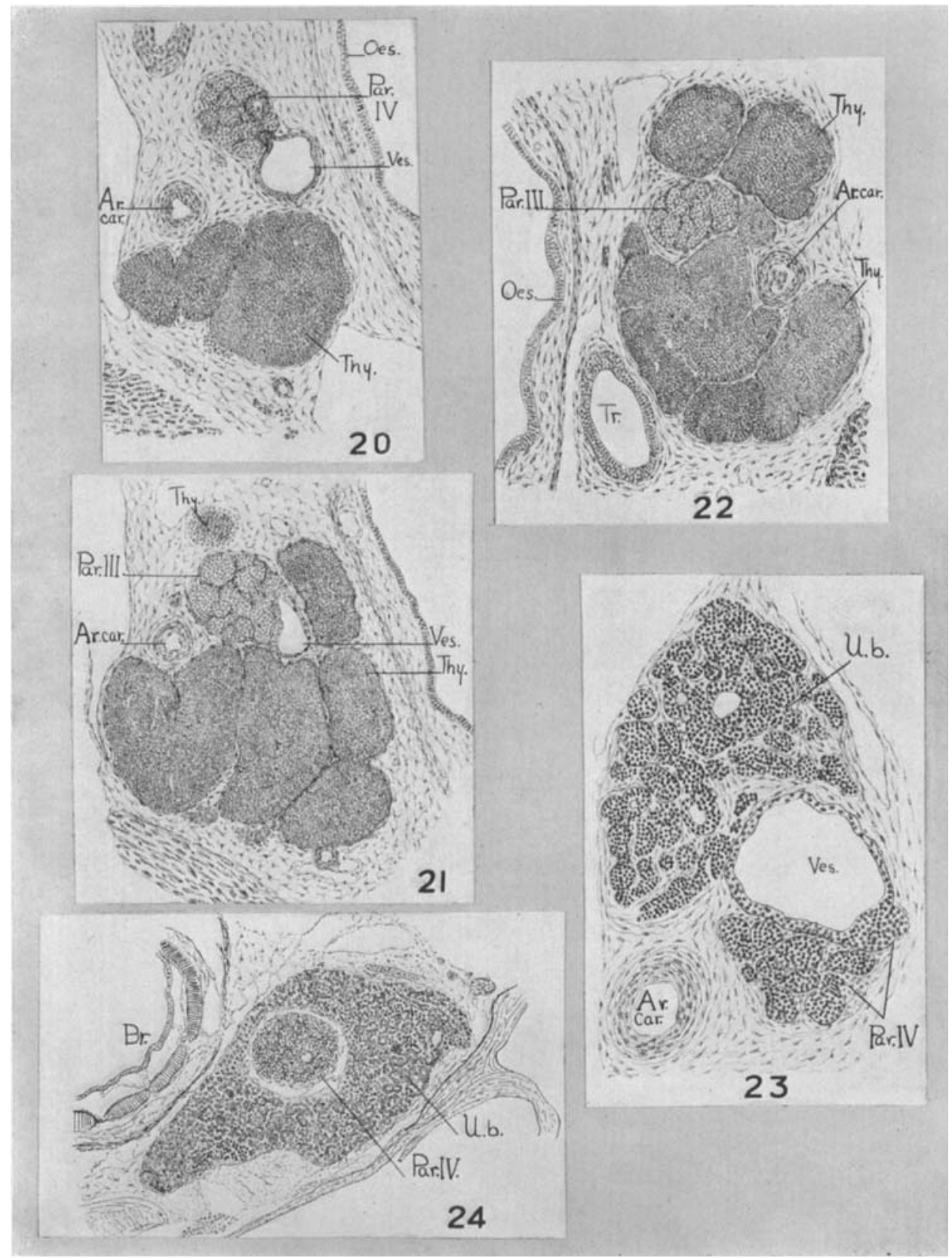

